\title{
Correction to: Genetic Evidence of Middle East Respiratory Syndrome Coronavirus (MERS-Cov) and Widespread Seroprevalence among Camels in Kenya
}

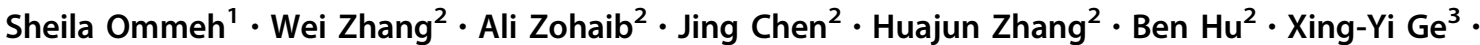

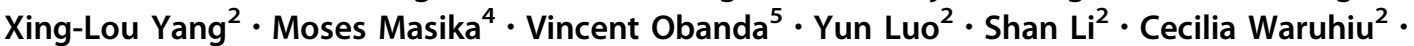 \\ Bei $\mathrm{Li}^{2} \cdot$ Yan $\mathrm{Zhu}^{2} \cdot$ Desterio Ouma ${ }^{6}$. Vincent Odendo ${ }^{6} \cdot \mathrm{Lin}^{-\mathrm{Fa}} \mathrm{Wang}^{7} \cdot$ Danielle E. Anderson $^{7}$. \\ Jacqueline Lichoti ${ }^{8} \cdot$ Erick Mungube $^{6} \cdot$ Francis Gakuya $^{5} \cdot$ Peng Zhou $^{2} \cdot$ Kisa-Juma Ngeiywa $^{8,9}$ • \\ Bing $\mathrm{Yan}^{2} \cdot$ Bernard Agwanda $^{10}$ (D) Zheng-Li Shi ${ }^{2}$ (I)
}

Published online: 28 February 2019

(c) Wuhan Institute of Virology, CAS 2019

\section{Correction to: Virologica Sinica (2018) 33:484-492 https://doi.org/10.1007/s12250-018-0076-4}

The acknowledgement section in the original article was published incorrectly.

The appropriate version is given below.

Acknowledgements We thank all staff of the Ministry of Health and Ministry of Agriculture Livestock, Fisheries and Irrigation, Chiefs and local assistants from County governments of West Pokot, Turkana, Baringo, Samburu,

Sheila Ommeh, Wei Zhang, Ali Zohaib and Jing Chen have contributed equally to this work.

The original article can be found online at https:// doi.org/10.1007/s12250-018-0076-4.

Bernard Agwanda

bagwanda@museums.or.ke

$\triangle$ Zheng-Li Shi

zlshi@wh.iov.cn

1 Institute for Biotechnology Research, Jomo Kenyatta University of Agriculture and Technology,

Nairobi 62000-00200, Kenya

2 CAS Key Laboratory for Special Pathogens and Biosafety, Wuhan Institute of Virology, Chinese Academy of Sciences, Wuhan 430071, China

3 College of Biology, Hunan University, Changsha 410006, China

4 Department of Medical Microbiology, University of Nairobi, Nairobi 30197-00100, Kenya

5 Veterinary Services Department, Kenya Wildlife Service, Nairobi 40241-00100, Kenya
Laikipia, Isiolo, Marsabit, Mandera, Wajir, Garissa, Tana River, Kitui, and Makueni; Kenya camel association; Kenya Wildlife Service; and National Museums of Kenya. Sheila Ommeh is a recipient of the Chinese Academy of Science Presidents International Fellowship Initiative (CAS-PIFI). This work was funded by Sino-Africa Joint Research Center (SAJC201313 and SAJC201605), External Cooperation Program of CAS (153211KYSB201 60001), and National Science and Technology Major Project (2018ZX10101004).
6 Veterinary Research Institute, Kenya Agriculture and Livestock Research Organization, Nairobi 57811-00200, Kenya

7 Veterinary Services Programme in Emerging Infectious Diseases, Duke-NUS Medical School, Singapore 169857, Singapore

8 Directorate of Veterinary Services, State Department of Livestock, Ministry of Agriculture, Livestock Fisheries and Irrigation, Nairobi 34188-00100, Kenya

9 Kenya Camel Association, Nairobi 30095-00100, Kenya

10 Department of Zoology, National Museums of Kenya, Nairobi 40658-00100, Kenya 